Case Report

\title{
Conservative Management, Follow-up and Perinatal Outcomes After Gestational Trophoblastic Disease with Coexistent Normal Fetus: Case Report
}

\author{
Herrera-Ortiz Alejandra ${ }^{1}$, Barrita-Domínguez Isela Juliana ${ }^{2}$, Morales-Domínguez Liliana ${ }^{3}$, \\ Rojas-Camacho Francisco Miguel $^{1}$ \\ ${ }^{1}$ Department of Gynecology and Obstetrics at General Hospital "Dr. Manuel Gea González”, México City, Mexico \\ ${ }^{2}$ Department of Maternal-Fetal Medicine at General Hospital “Dr. Manuel Gea González”, México City, Mexico \\ ${ }^{3}$ Department of Hysteroscopy at General Hospital “Dr. Manuel Gea González”, México City, Mexico
}

Email address:

dra.lilimoralesd@gmail.com (Morales-Domínguez L.)

\section{To cite this article:}

Herrera-Ortiz Alejandra, Barrita-Domínguez Isela Juliana, Morales-Domínguez Liliana, Rojas-Camacho Francisco Miguel. Conservative Management, Follow-up and Perinatal Outcomes After Gestational Trophoblastic Disease with Coexistent Normal Fetus: Case Report. Journal of Gynecology and Obstetrics. Vol. 7, No. 2, 2019, pp. 36-40. doi: 10.11648/j.jgo.20190702.12

Received: January 23, 2019; Accepted: March 30, 2019; Published: April 22, 2019

\begin{abstract}
Background: Gestational trophoblastic disease (GTD) is the consequence of a genetic alteration that happens during fecundation. Is the term used to describe malignant lesions that originates in the chorionic villi an extra villous trophoblast. Molar pregnancies can be subdivided into complete (CM) and partial moles (PM) based on genetic and histopathological features. Case report: 23-year old patient, who presents an ultrasound which revealed a singleton pregnancy with no fetal structural abnormalities, and fetal biometry consistent with gestational age $(16 \mathrm{w}+6 \mathrm{~d})$. There was a placenta with focal areas of enlargement associated with numerous lucent cyst, and normal amniotic fluid, compatible with partial molar pregnancy in association with a normal fetus. After risks of subsequent fetal and maternal complications were explained to the patient and her family, it was elected to continue with her pregnancy; patient went under cesarean delivery at $31 \mathrm{w} 3 \mathrm{~d}$ because low amniotic fluid levels (oligohydramnios) and abnormal fetal well-being tests.
\end{abstract}

Keywords: Gestational Trophoblastic Disease, Partial Mole, Partial Mole Associated with Normal Fetus

\section{Introduction}

Gestational trophoblastic disease is a heterogeneous group of diseases that includes precancerous lesions such as hydatidiform mole and lesions with malignant potential, grouped together in the category of gestational trophoblastic tumours (invasive mole, choriocarcinoma, placental site trophoblastic tumour, and epithelioid trophoblastic tumour) [1]. Hydatidiform moles are intriguing pathologic entities representing abnormal placental villous tissue with unique genetic profiles and a wide spectrum of morphologic features, which makes accurate diagnosis challenging [2]. Molar pregnancies are characterized by varying degrees of trophoblastic proliferation and vesicular swelling of placental villi associated with an absent or an abnormal fetus/embryo.
Two syndromes of hydatidiform mole have been described based on both morphologic and cytogenetic criteria [1, 2]:

i Complete hydatidiform moles undergo early and uniform hydatid enlargement of villi in the absence of a fetus or embryo, the trophoblast is consistently hyperplastic with varying degrees of atypia, and villous capillaries are absent. Approximately $90 \%$ of complete moles are $46, \mathrm{XX}$, originating from duplication of the chromosomes of an haploid sperm after fertilization

ii Partial hydatidiform moles demonstrate identifiable fetal or embryonic tissue, chorionic villi with focal edema that can vary in size and shape. Most partial moles have a triploid karyotype (usually 69, XXY) resulting from the fertilization of a ovum by 2 sperms. Less frequently they have a diploid karyotype. 
A case of a gestational trophoblastic disease in association with a normal diploid fetus is presented, which result in a successful pregnancy outcome with preterm viable female fetus.

\section{Case report:}

23 year-old patient, with history of a miscarriage, and uncertain last menstrual period, with first trimester spotting with normal vital signs. During examination she presents a gravid uterus of $19 \mathrm{~cm}$, no uterine contractions, and a singleton fetus with normal audible heart-rate of 145 beats per minute (bpm). No abnormalities were noted during genital examination.

The ultrasound examination performed on September 22, 2016 revealed: A singleton pregnancy, normal fetal heart rate of $145 \mathrm{bpm}$, amniotic fluid index of $3 \mathrm{~cm}$, no fetal abnormalities and fetal biometry consistent with 16w 6d gestational age. There was a low implantation placenta with focal area of enlargement associated with numerous lucent cyst (approximately $60 \%$ of the uterine cavity) (Figure 1, figure 2).

Cervical length of $3.8 \mathrm{~cm}$ with no abnormalities, and cyst images around internal cervical os. No fetal abnormalities or second trimester ultrasound markers for chromosomal abnormalities. Concluding a gestational trophoblastic disease (partial hydatidiform mole) in association with normal fetus. Amniocentesis was not performed.

The risk of subsequent fetal and maternal complications was explained to the patient and her family. The patient elected to continue her pregnancy and received close observation at outpatient clinic.

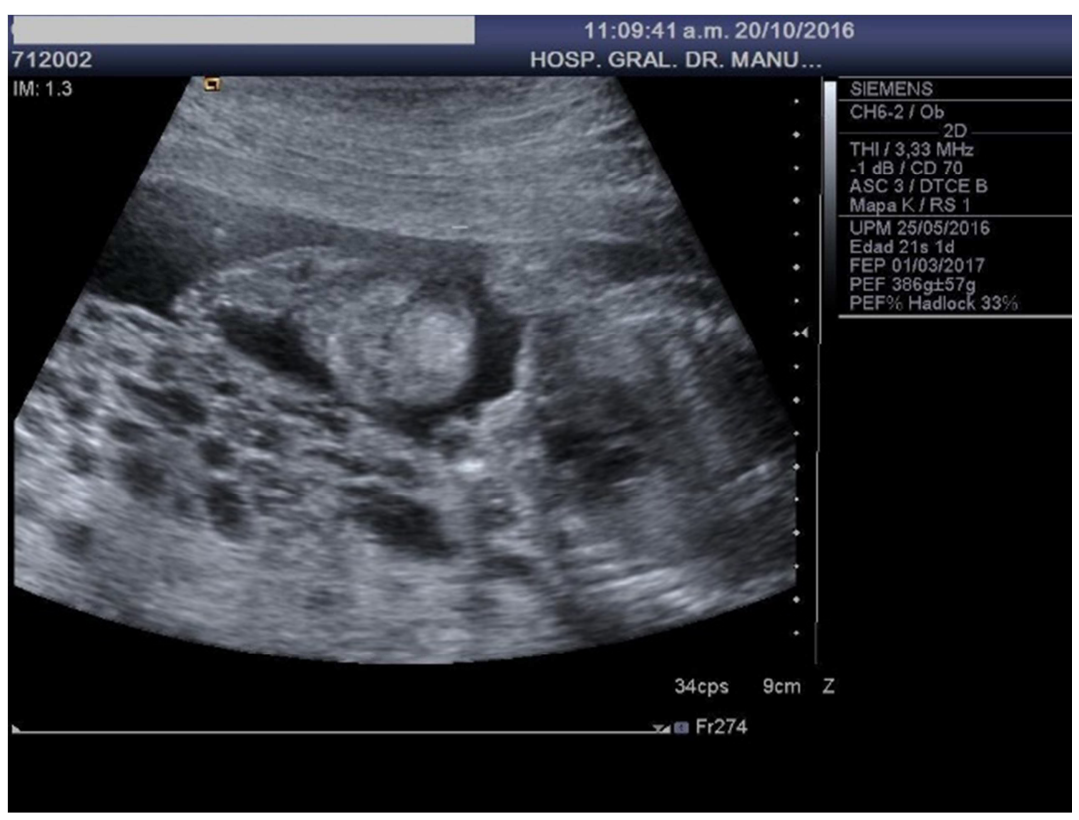

Figure 1. Fetal examination by ultrasound.

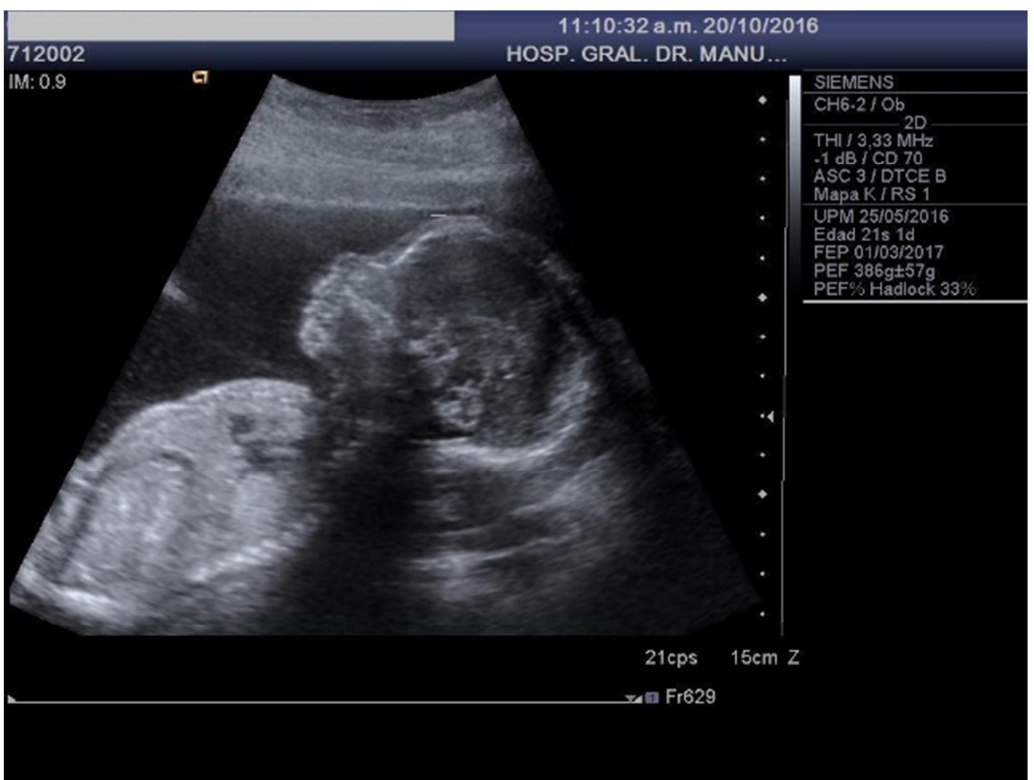

Figure 2. Placenta with lucent cysts. 
Antenatal Surveillance:

Initial test results were normal with white blood cells of $12.3 \mathrm{ml} / \mathrm{microL}$, hemoglobin $14.0 \mathrm{~g} / \mathrm{Dl}$, hematocrit of $41.9 \%$, platelets $215 \mathrm{ml} / \mathrm{microL}$, glucose $84 \mathrm{mg} / \mathrm{dl}$, uric nitrogen $7.2 \mathrm{mg} / \mathrm{Dl}$, creatine $0.6 \mathrm{mg} / \mathrm{dl}$, total bilirrubin $0.08 \mathrm{mg} / \mathrm{dl}$, indirect bilirrubin $0.24 \mathrm{mg} / \mathrm{dl}$, alanine aminotransferase (ALT) $13 \mathrm{IU} / \mathrm{L}$, aspartate aminotransferase (AST) $21 \mathrm{IU} / \mathrm{L}$, lactic acid dehydrogenase $166 \mathrm{IU} / \mathrm{L}$. Normal urine test. A positive hemotype. Thyroid function tests: TRH stimulation test 2.54 $\mu \mathrm{IU} / \mathrm{ml}$, total Triiodothyronine (TT3) $1.06 \mathrm{ng} / \mathrm{dl}$, Free triiodothyronine 3.0ng/dl, Serum thyroxine (T4) $9.96 \mu \mathrm{g} / \mathrm{dl}$, free thyroxine (FT4) $0.87 \mathrm{ng} / \mathrm{dl}$. Except for high level of human chorionic gonadotropin (hCG) in 150,804.63 UI with $16 \mathrm{w} 6 \mathrm{~d}$. These laboratory test and serial biometrics of the fetus were measured during gestation.

After five evaluations at outpatient clinic, there were no evidence of maternal or fetal abnormalities, with serum titers of B-hCG of 73,304.50 IU at 29 weeks gestation. The ultrasound examination showed normal biometric fetus until 26 weeks gestation. The clinical course was smooth until the 29th gestational week, when the ultrasound revealed a fetal biometry consistent with 27 weeks gestation, low implantation placenta with focal area of enlargement with lucent cyst, amniotic fluid index of $2.8 \mathrm{~cm}$, estimated fetal weight of $984 \mathrm{~g}$ $<4$ th percentile, normal Doppler study, resulting in small-for-gestational age fetus.

After two weeks the mother perceives a diminution in fetal movements. The patient revealed normal vital signs, no rupture of the membranes or any other abnormality. An ultrasound examination was performed revealing fetal biometrics consistent with $27 \mathrm{w}$ 1d gestation, differing by 4 weeks with her first ultrasound (16w6d), and oligohydramnios was detected with amniotic fluid index of $3.7 \mathrm{~cm}$, with biophysical profile score of 6 . Corticosteroids were given to promote fetal lung maturation. After 48 hours, the mother still perceives diminished fetal movements, a new ultrasound exploration is performed, consistent with 27 weeks and 3 days, 4 weeks smaller than expected in comparison with the second trimester ultrasound, pelvic presentation of the fetus with a heart rate of 150 beats per minute, with an estimated weight of 1333grs (P: 2), fundal placenta, amniotic fluid index of $1.6 \mathrm{~cm}$ (low amniotic fluid in comparison with last ultrasound), it was not possible to realize the Doppler study. Laboratory test within normal results: with white blood cells of $13.3 \mathrm{ml} / \mathrm{microL}$, hemoglobin $12.6 \mathrm{~g} / \mathrm{Dl}$, Hematocrit of $37.8 \%$, platelets $160 \mathrm{ml} / \mathrm{microL}$, glucose $103 \mathrm{mg} / \mathrm{dl}$, uric nitrogen $16.5 \mathrm{mg} / \mathrm{Dl}$, creatine $0.78 \mathrm{mg} / \mathrm{dl}$, normal nonstress test, and altered biophysical profile, so it is decided to deliver the baby to prevent pregnancy loss and fetal hypoxia because of the concomitant partial mole, low amniotic fluid, intrauterine growth restriction and non-reassuring biophysical profile test.

A preterm live baby girl of 925grams, Apgar score 8/9, Silverman score 1, 32 weeks of age, was delivered (Figure 3), who was admitted to the Intensive Care Unit. Placental tissue weighting 700 grams with multiple vesicles on the surface of the placenta (Figure 4), and a blood loss of $1500 \mathrm{cc}$.
After 6 months of follow up, the value of $\mathrm{HGCH}$ was negative, with no need of chemotherapy.

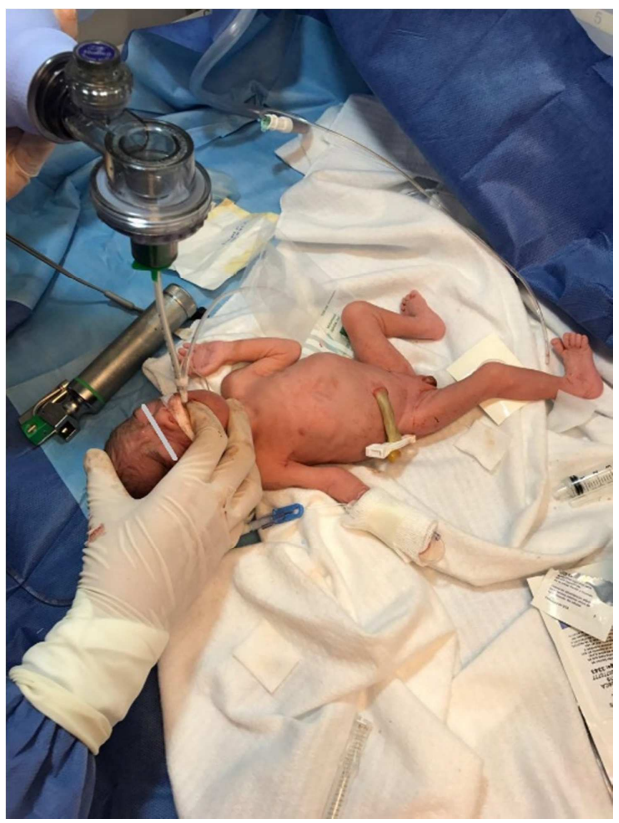

Figure 3. Preterm live baby girl.

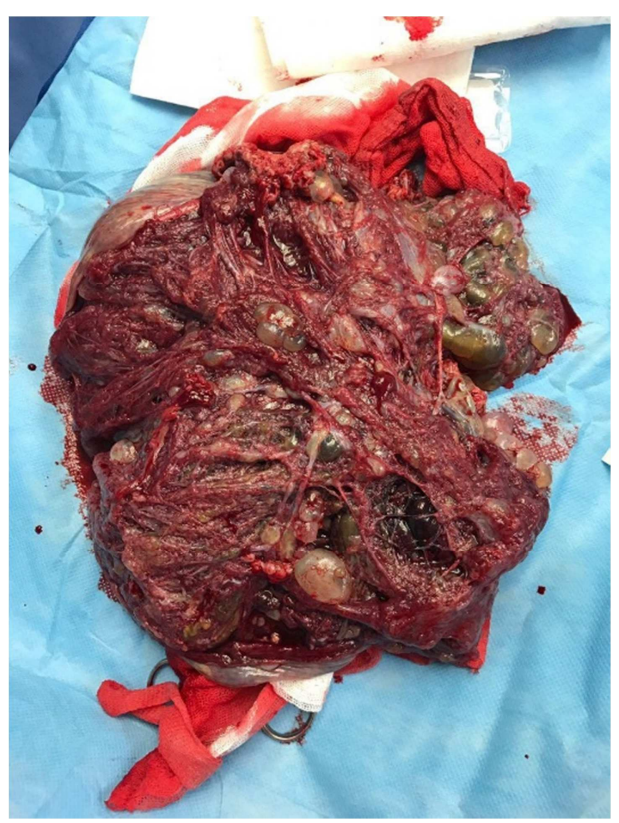

Figure 4. Macroscopic view of the placenta.

\section{Discussion}

Gestational trophoblastic disease is the result of a genetic alteration during the fertilization process which leads to a spectrum of cellular proliferations arising from the placental villous trophoblast [3].

The incidence of GTD is approximately 1 to 3 in 1,000 pregnancies, with an increased incidence in Middle East, Latin America, and Africa [4]. Jauniax and cols report an incidence of partial hydatidiform mole to range from $1-3$ in 665 
pregnancies; attributed to a number of factors such as inconsistencies in case definitions such as miscarriages instead of gestational trophoblastic disease [5]. In Mexico the estimated incidence is 2.4 in 1000 pregnancies $[5,6]$. The identification and classification of molar pregnancies is desirable due to a $15 \%$ risk of choriocarcinoma development in the case of a complete mole, compared to a $0.5 \%$ risk for a partial mole. [7]

Both complete hydatidiform mole and coexisting normal fetus (CHMCF) and partial hydatidiform mole can be found in association with a live fetus and a placenta displaying a molar degeneration. The differential diagnosis is important because the fetus in CHMCF has a chance to survival, while the fetus of partial mole tends to die [10]. Partial molar pregnancy with coexisting fetus and diploid karyotype is a rare complication with an incidence of 1 in 22,000 - 100,000 pregnancies [8,9]. Whereas women usually present early onset hyperemesis, preeclampsia and intrauterine growth restriction. It usually derives from dispermic fertilization of an haploid normal oocyte and produces a triploid set of chromosomes, usually the fetus shows multiple malformations. However in some situations molar changes in placenta are associated with normal diploid fetus. In cases of such association other possibilities should be considered [5, 9]. The first is a twin pregnancy with one normal fetus (normal placenta) and another complete mole, the second is a twin pregnancy with fetus and normal placenta and partial hydatidiform moles, and the third and less common is a pregnancy with normal singleton fetus with partial molar placenta, where the fetus must have normal karyotype to survive in utero, although its placenta can have some chromosomal variation, from diploidy of the amnion to triploidy of the chorionic villi $[5,7,8,11]$. The majority of pregnancies in which molar change has been reported in association with a live fetus represent dizygotic twin pregnancies in which one fertilization results in a complete hydatidiform mole and the other a normal co-twin. In such cases, there is usually a clear distinction, both sonographically and pathologically, between the molar and non-molar regions of the placenta [18]. A PubMed research about the third type of molar pregnancy has been reported a few times during the period between 1975 to 2018 finding 7 to 13 cases in the medical literature [8, 14], and it has been documented to be more in female fetuses with female:male of approximately 3.5:1 [12]. In this case, a preterm baby girl was delivered with no physical malformations during ultrasound examinations, and a normal karyotype 46XX.

In 1993 Sarno and cols reported a partial mole pregnancy coexisting with a normal fetus, and a conservative management was decided in base of multiple cytogenetic studies: amniocentesis and chorionic villous biopsy to determine a normal fetus karyotype, and a discordant placental tissue karyotype [7]. Kawasaki and cols reported a literature search, which yielded 18 cases of a singleton, diploid fetus with partial molar pregnancy. The mean gestational age at delivery was $24.5+/-6.2$ weeks, and fetuses survived outside the uterus in only four cases (22.2\%) [12]. Management of molar changes associated with normal appearing fetus still remains challenging, with a high risk for both mother and fetus [5]. The main complications during pregnancy coexisting with normal fetus are: fetal malformations, malignant trophoblastic changes and maternal complications such as preeclampsia. In the presence of any of this termination of pregnancy should be considered [15, 17]. For and adequate prenatal surveillance, Sak M. E. et cols recommend:

(a) To determine fetal karyotype.

(b) To determine the portion of normal placental tissue, and the percentage of hydatidiform degeneration.

(c) Early diagnosis of maternal complications such as preeclampsia, premature labor, thyroid disease and risk of hemorrhage.

(d) Ultrasound examination for possible fetal malformations.

(e) Fetal screening for anemia due to maternal bleeding.

All of these recommendations with the objective of discussing with the mother whether the pregnancy should continue or not. The surveillance of HCGH and ultrasound examinations are important tools for these cases [18]. The follow-up of the values of $\mathrm{HCGH}$ in patients with partial hydatidiform mole should be regular during a year, because of the risk of developing choriocarcinoma and consequent risk of death. Even though the need of chemotherapy is not often needed [16].

\section{Conclusion}

In the case of a molar pregnancy coexisting with a normal fetus diagnosed by ultrasound, amniocentesis and corial villi biopsy are essential for confirming the diagnosis, although this entity is very rare for establishing therapeutically strategies. $\beta$-human chorion gonadotropin $(\beta$-hCG) plays a crucial role in diagnosis and monitoring therapeutic effects. Since the definitive diagnosis cannot be obtained by histology in most cases, persistent or recurrent disease is diagnosed by elevated or persistent serum levels of $\beta$-hCG [20]. In this case there were no evidence of fetal malformations during the ultrasound examinations, only the placental trophoblastic proliferation, however, the postnatal karyotype was 46XX. The development of the baby girl keeps normal. The histopathological report of the placenta was partial hydatidiform mole. Literature suggests to individualize every patient, and take therapeutically measures according to the clinical presentation. If the patient decides to continue with the pregnancy, she should understand the obstetrical risks such as preeclampsia, premature rupture of the membranes, preterm labor, oligohydramnios, fetal distress or even maternal or fetal death.

\section{References}

[1] Kubelka-Sabit K, Jasar D, Filipovski V, Bozinovski G, Plaseska-Karanfilska D. Molecular an histological characteristics of early triploid and partial molar pregnancies. Pol J Pathol. 2017;68(2):138-143. 
[2] Hui P, Buza N, Murphy KM, Ronnett BM. Hydatidiform Moles: Genetic Basis and Precision Diagnosis. Annu Rev Pathol. 2017 Jan 24;12:449-485.

[3] Protocolos SEGO. Embarazo molar. Prog Obstet Ginecol 2004; $47(8): 400-4$

[4] Juárez Azpilcueta A, Islas Domínguez L, Duran Padilla MA. Mola Hidatiforme Parcial con feto vivo del segundo trimestre. Rev Chil Obstet Ginecolg 2010; 75(2): 137-139.

[5] Surendran S, Thomas T, Vishnupriya VS. Partial Molar Pregnancy with a Normal Fetus with Complete Placenta Previa. J Obstet Gynaecol India 2018 Jun; 68(3):227.228.

[6] Galaz-Montoya CI, Razo Aguilera G, Grether-González P, Aguinaga-Ríos M. Aspectos genéticos de la mola hidatiforme. Perinatol Reprodu Hum 2015; 29(3): 113-117

[7] Duffy L, Zhang L, Sheath K, Love DR, George AM. The Diagnosis of Choriocarcinoma in Molar Pregnancies: A Revised Approach in Clinical Testing. J Clin Med Res. 2015 Dec;7(12):961-6

[8] Morales García V, Bautista Gómez E, Vásquez Santiago E, Santos Pérez U. Embarazo molar parcial: reporte de un caso y revisión de la bibliografía. Ginecol Obstet Mex 2011;79(7):432-435.

[9] Lara MF, Alvarado MA, Candelaria M, Arce SC. Enfermedad trofoblástica gestacional. Experiencia en el Instituto Nacional de Cancerología. Ginecol Obstet Mex 2005; 73: 308-14.

[10] Sak ME, Soydinc HE, Evsen MS, Firat U. Diploide karyotype partial mole coexisting with live term fetus-case report and reviewd of the world literature. Ginekol Pol. 2012 Oct;83(10):789-91

[11] Koregol M, Bellad M, Malapati C. Partial Hydatiform Mole with a Live Fetus- A Rare Entity. Journal of SAFOG. September 2009; 1 (3): 77-79
[12] Kawasaki K, Kondoh E, Minamiguchi S, Matsuda F, Higasa K, Fujita K, Mogami H, Chigusa Y, Konishi I. Live-born diploid fetus complicated with partial molar pregnancy presenting with pre-eclampsia, maternal anemia, and seemingly huge placenta: A rare case of confined placental mosaicism and literatura review. J Obstet Gynaecol Res. 2016 Aug;42(8):911-7.

[13] Fan-Ping C. Molar pregnancy and living normal fetus coexisting until term: prenatal biochemical and songraphic diagnosis. Human Reproduction 1997; 12 (4): 853-856.

[14] Rahamni M, Parviz S. A case report of partial molar pregnancy associated with a normal appearing dizygotic fetus. Asian Pacific Journal of Reproduction 2016; 5(2): 171.173.

[15] Ramani B et al. Living fetus without congenital malformation in a singleton partial hydatiform molar pregnancy: a case report and review of the literature. In J Reprod Contracept Obstet Gynecol. 2014 Dec: 3(4): 1130-1133.

[16] Tizita A. Partial mole with coexisting term fetus. A case report. Ethiopian Journal of Reproductive Health 2018; 10 (2): 53-56.

[17] Deever R, Engin- Üstün Y, Gün-Erylmaz Ö, Akbaba E, et al. Molar Pregnancy with a Co-Existing Viable Fetus. J Clin Anal Med 2015; 6(1): 88-90.

[18] Makrydimas G, Serbire NJ, Thornton SE, Zagorianakou N, Lolis D, Fisher RA. Complete hydatidiform mole and normal live birth: a novel case of confined placental mosaicism: case report. Hum Reprod. 2002 Sep;17(9):2459-63.

[19] Stevens FT, Katzorke N, Tempfer C, Kreimer U, Gizjak GI, Fleisch MC, Fehm TN. Gestational Trophoblastic Disorders: An Update in 2015. Geburtshilfe Frauenheilkd. 2015 Oct;75(10):1043-1050.

[20] Imafuku H, Miyahara Y, Ebina Y, Yamada H. Ultrasound and MRI Findings of Twin Pregnancies with Complete Hydatidiform Mole and Coexisting Normal Fetus: Two Case Reports. Kobe J Med Sci. 2018;64(1):E1-E5. 